\title{
Cross-Linked Multimeric Pro-Peptides of Type III Collagen (PC3X) in Hepatocellular Carcinoma - A Biomarker That Provides Additional Prognostic Value in AFP Positive Patients
}

This article was published in the following Dove Press journal:

Journal of Hepatocellular Carcinoma

\author{
Christina Jensen (iD) ${ }^{1,2}$ \\ Signe Holm Nielsen ${ }^{1,3}$ \\ Mohammed Eslam ${ }^{4}$ \\ Federica Genovese (iD ${ }^{\prime}$ \\ Mette Juul Nielsen' \\ Roslyn Vongsuvanh ${ }^{4}$ \\ Raj Uchila (1D ${ }^{4}$ \\ David van der Poorten ${ }^{4}$ \\ Jacob George 4 \\ Morten Asser Karsdal (D) \\ Diana Julie Leeming' \\ Nicholas Willumsen' \\ 'Biomarkers \& Research, Nordic \\ Bioscience, Herlev, Denmark; ${ }^{2}$ Biotech \\ Research \& Innovation Centre (BRIC), \\ University of Copenhagen, Copenhagen, \\ Denmark; ${ }^{3}$ Biotechnology and \\ Biomedicine, Technical University of \\ Denmark, Lyngby, Denmark; ${ }^{4}$ Storr Liver \\ Centre, Westmead Institute for Medical \\ Research, Westmead Hospital and \\ University of Sydney, Sydney, NSW, \\ Australia
}

\begin{abstract}
Purpose: Non-invasive biomarkers for diagnosing and prognosing hepatocellular carcinoma (HCC) are urgently needed. Cirrhosis is present in $80-90 \%$ of HCC patients. Cirrhosis is characterized by deposition and cross-linking of collagens that have crucial roles in HCC initiation and progression. We evaluated circulating cross-linked pro-peptides of type III collagen (PC3X) as a diagnostic and prognostic biomarker for HCC.

Patients and Methods: PC3X was measured by ELISA in plasma from patients with HCC $(\mathrm{n}=79)$, cirrhosis $(\mathrm{n}=86)$, non-cirrhotic hepatitis- $\mathrm{B}$ infection $(\mathrm{n}=74)$ and from healthy controls $(\mathrm{n}=44)$. PC3X was compared to the liver fibrosis marker PRO-C3 and the HCC tumor-cell derived marker alpha-fetoprotein (AFP). Diagnostic and prognostic potential was evaluated by AUROC and by calculating hazard ratios (HR) for progression-free survival (PFS) and overall survival (OS).
\end{abstract}

Results: PC3X, PRO-C3 and AFP were significantly elevated in patients with HCC compared to other liver diseases and healthy controls $(p=0.0002, p<0.0001)$. In patients with normal AFP $(<20 \mathrm{IU} / \mathrm{mL})$, PC3X and PRO-C3 separated HCC from cirrhosis with an AUROC of 0.72 and 0.68 , respectively. High PC $3 \mathrm{X}$ and AFP predicted for poor PFS $\left(\mathrm{HR}_{\mathrm{PC} 3 \mathrm{X}}=1.80, p=0.032 ; \mathrm{HR}_{\mathrm{AFP}}=1.70, p=0.031\right)$ and $\mathrm{OS}\left(\mathrm{HR}_{\mathrm{PC} 3 \mathrm{X}}=2.12, p=0.024 ; \mathrm{HR}_{\mathrm{AFP}}\right.$ $=2.55 ; p=0.003$ ), whereas PRO-C3 did not (PFS: $\mathrm{HR}=1.19, p=0.059$ and OS: $\mathrm{HR}=1.12$, $p=0.324$ ). PC3X was independent of AFP (PFS: $\mathrm{HR}=1.74, p=0.045$ and OS: $\mathrm{HR}=2.21$, $p=0.018$ ) and combining the two improved prognostic value (PFS: $\mathrm{HR}=2.66, p=0.004$ and OS: $\mathrm{HR}=5.86, p<0.0001)$.

Conclusion: PC3X is associated with HCC independent of AFP and provides diagnostic and prognostic value for HCC patients. If validated, this suggests that PC $3 \mathrm{X}$ has biomarker potential for HCC.

Keywords: tumor microenvironment, extracellular matrix, fibrosis, liver cancer

\section{Introduction}

Hepatocellular carcinoma (HCC) remains a major global health problem, and in contrast to most other types of cancer, its incidence has increased over the last decades. ${ }^{1} \mathrm{HCC}$ is highly lethal and the 5 -year survival rate is approximately $10 \% .{ }^{2,3}$ This poor prognosis is due to both late-stage diagnosis and limited treatment options.

Currently, there is compelling evidence that earlier stage detection of HCC via surveillance is more amenable to curative therapies and improved overall survival
Correspondence: Christina Jensen Nordic Bioscience, Herlev Hovedgade 205-207, Herlev 2730, Denmark

Tel: +4544525252

Fax: +4544525251

Email chj@nordicbio.com
Journal of Hepatocellular Carcinoma 2020:7 30I-3/3 
(OS). ${ }^{4}$ Though all current guidelines recommend surveillance for HCC in patients with cirrhosis, the recommended approaches are not consistent. While the European Association for the Study of the Liver (EASL) recommends the use of ultrasonography alone, ${ }^{5}$ the American Association for the Study of Liver Diseases (AASLD) recommends the use of ultrasonography with or without alpha-fetoprotein $(\mathrm{AFP})^{6}$ and the Asian Pacific Association for the Study of the Liver (APASL) recommends the use of both ultrasonography and AFP. ${ }^{7}$ Though AFP is the gold-standard serum marker for HCC, the utility of AFP for surveillance is limited by its low sensitivity and specificity. ${ }^{8}$ A large proportion of HCC patients (42\%) in fact do not have elevated levels of AFP (>20 IU/mL), ${ }^{9}$ emphasizing the urgent need to develop better biomarkers.

Cirrhosis, a consequence of fibroblast activation leading to extracellular matrix (ECM) deposition is the major risk factor for $\mathrm{HCC}$ and is the substrate on which tumors develop in $80-90 \%$ of cases. ${ }^{10}$ Cross-linking of the ECM is important as it contributes to tissue stiffness thereby changing its quality. Mounting evidence also suggests that
ECM deposition and stiffness play key roles in HCC initiation, progression and metastasis. ${ }^{11,12}$ Cross-linking of collagens is catalyzed by enzymes such as lysyl oxidase (LOX), its family members LOX-like (LOXL) $1-4$ and transglutaminase 2 (TG2). ${ }^{13,14}$ LOXL2-induced tissue stiffness has been shown to induce intrahepatic and extrahepatic metastasis in HCC, while TG2 is elevated in HCC patients and is associated with $\mathrm{HCC}$ invasion. ${ }^{15-17}$

Type III collagen has been detected in HCC patients in a study from $1997 .{ }^{18}$ In liver fibrosis, type III collagen production is markedly up-regulated. ${ }^{19}$ During its formation and accumulation, pro-peptides are cleaved from type III pro-collagen and released into the circulation. Notably, we have shown that the biomarker PRO-C3, which targets the $\mathrm{N}$-proteinase ADAMTS2 cleavage site of the N-terminal pro-peptide of type III collagen and consequently measures true formation of type III collagen, is a robust biomarker of liver fibrosis (Figure 1). PRO-C3 has been widely investigated as a diagnostic, prognostic, and efficacy biomarker, as well as a predictor of clinical outcome across different liver diseases. ${ }^{19-26}$ Elevated PRO-C3 levels have furthermore

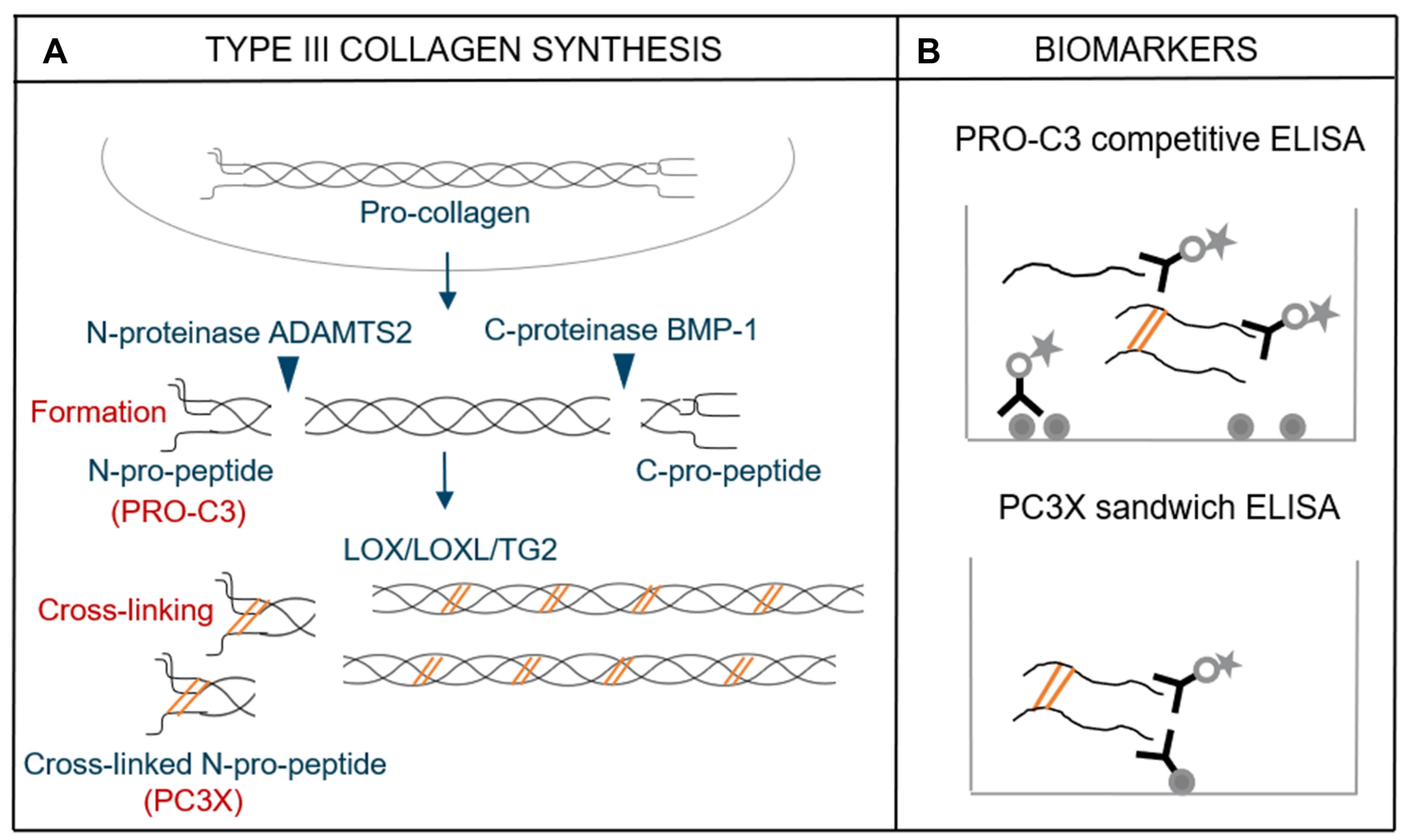

Figure I Biomarkers of type III collagen formation and cross-linking. (A) After pro-collagen triple helix folding ( $\alpha$ I chains), the N-and C-pro-peptides are cleaved in the extracellular space by the N-proteinase ADAMTS2 and the C-proteinase BMP-I. Type III collagen molecules are cross-linked by the enzymes lysyl oxidase (LOX), LOX-like (LOXL) I-4 and transglutaminase 2 (TG2). (B) PRO-C3 measures type III collagen formation. PRO-C3 is based on a competitive ELISA that targets the ADAMTS2 cleavage site of the $\mathrm{N}$-terminal pro-peptide and can measure single-and doublet stranded pro-peptides. PC3X measures type III collagen formation and cross-linking. PC3X is based on a sandwich ELISA that targets the same cleavage site as PRO-C3 but only measures cross-linked multimeric pro-peptides. 
been associated with poor outcomes in breast cancer and malignant melanoma. ${ }^{27,28}$ However, PRO-C3's role in HCC remains to be established. The PRO-C3 biomarker does not differentiate between single stranded or cross-linked N-terminal pro-peptides (Figure 1). Because liver fibrosis progression and HCC growth and metastasis are associated with matrix stiffness and cross-linking of collagens, ${ }^{11,15-17,29}$ we hypothesized that an ECM derived biomarker only measuring cross-linked type III collagen pro-peptides would have diagnostic and prognostic potential for HCC. To investigate this, we developed a sandwich ELISA to measure circulating cross-linked multimeric pro-peptides of type III collagen (PC3X) (Figure 1) and evaluated its biomarker potential in $\mathrm{HCC}$ in comparison with PRO-C3 and AFP.

\section{Patients and Methods Patient Cohort}

This case-control study involved four independent groups comprising a total of 283 participants (HCC $(n=79)$, cirrhosis $(n=86)$, non-cirrhotic hepatitis $B$ virus (HBV) infection $(n=74)$ and healthy controls $(n=44))$ recruited from a single tertiary liver clinic in Sydney, Australia. The HCC patients had different etiologies and were diagnosed by characteristic radiological appearances on 4-phase CT or MRI demonstrating the combination of hypervascularity in late arterial phase (enhancement) and washout on the portal venous and/or delayed phases according to EASL guidelines, ${ }^{5}$ or by histology. The absence of HCC was based on imaging evidence on the absence of space-occupying lesions in the liver consistent with HCC on serial imaging every 6 months for the preceding 12 months. Clinical staging of HCC was according to the Barcelona Clinic Liver Cancer (BCLC) system. EDTA plasma was taken at the time of diagnosis, prior to the initiation of treatment. The HCC patients received different therapeutic options: best supportive care $(n=3)$, radiofrequency ablation $(n=15)$, selective internal radiation therapy (Sirspheres) $(n=5)$, sorafenib $(n=14)$, surgical $(n=11)$ and transarterial chemoembolization (TACE) $(n=31)$. Progression-free survival (PFS) and OS were estimated from baseline.

The cirrhosis group comprised individuals with different etiologies, diagnosed based on liver biopsy, a fibroscan value of greater than $14 \mathrm{kPa}$, or clinical feature suggestive of cirrhosis (presence of varices, splenomegaly or thrombocytopenia). The HBV infected group included patients with chronic HBV in the absence of cirrhosis. The healthy control group comprised individuals recruited through advertisements in local newspapers and at the hospital. All had normal physical examinations and liver tests, negative viral hepatitis serology and no history of liver disease. The study protocol was approved by the Human Ethics Committee of the Sydney West Area Health Service (HREC No.2002/12/4.9 (1564)) in compliance with the Helsinki Declaration. Written informed consent was obtained from all participants.

\section{Clinical and Laboratory Data}

Demographic and clinical data, including age, gender, body mass index (BMI), etiology ( $\mathrm{HCV}, \mathrm{HBV}$, alcoholic liver disease, non-alcoholic steatohepatitis), liver parameters (diabetes status, levels of bilirubin, albumin, alanine transaminase (ALT), aspartate transaminase (AST), platelet count (PLT) and AFP) and tumor-related variables (BCLC stage, Child-Pugh score, size of largest lesion, number of lesions, existence of metastasis and existence of portal vein invasion) are shown in Table 1. Routine biochemical tests including bilirubin, albumin, ALT, AST, PLT and AFP were assessed in fasting blood samples by standard methods and assays at baseline.

\section{ELISA Measurements - Type III Collagen}

A monoclonal antibody was raised against the $\mathrm{N}$-proteinase generated neo-epitope of the N-terminal pro-peptide of type III collagen and used to develop a technically robust sandwich ELISA based on two monoclonal antibodies (PC3X) (see Text, Supplemental Digital Content 1, which includes detailed methods about PC3X assay development, procedure and technical evaluation) and (see Text and Table in Supplemental Digital Content 2, which show the technical evaluation of the PC3X assay).

The procedure in brief, streptavidin-coated microtiter plates were coated with a biotin-labeled catcher antibody specific towards the N-proteinase cleavage site of the $\mathrm{N}$-terminal pro-peptide of type III collagen and incubated for 30 minutes at $20^{\circ} \mathrm{C}$. Standard, controls or pre-diluted EDTA plasma sample were added followed immediately by addition of assay buffer and incubated for 20 hours at $4^{\circ} \mathrm{C}$. Then, horseradish peroxidase (HRP)-labeled detector antibody was added and incubated for 1 hour at $20^{\circ} \mathrm{C}$. Next, tetramethylbenzidine (TMB) was added and incubated for 15 minutes at $20^{\circ} \mathrm{C}$. All incubations included shaking of the plates followed by five times washing. To stop the reaction of TMB, sulfuric acid was added, and the 
Table I Patient Characteristics: Liver Diseases and Healthy Controls

\begin{tabular}{|c|c|c|c|c|c|}
\hline \multirow[t]{2}{*}{$\mathbf{n}$} & Healthy Controls & Non-Cirrhotic HBV & Cirrhosis & HCC & \multirow[t]{2}{*}{ P-value } \\
\hline & 44 & 74 & 86 & 79 & \\
\hline Age (years), mean \pm SD & $53.8(7.6)$ & $58.6(9.1)$ & $58.8(10.0)$ & $62.0(11.6)$ & 0.0004 \\
\hline Gender (male), n (\%) & $4 I(93.2)$ & $63(85.1)$ & $75(87.2)$ & 71 (89.9) & 0.567 \\
\hline BMI, mean \pm SD & $25.9(2.9)$ & $25.6(4.2)$ & $29.4(5.6)$ & $28.1(6.0)$ & $<0.0001$ \\
\hline \multicolumn{6}{|l|}{ Etiology } \\
\hline $\mathrm{HCV}, \mathrm{n}(\%)$ & $\mathrm{n} / \mathrm{a}$ & $0(0)$ & $43(50.0)$ & $38(48.1)$ & $<0.0001$ \\
\hline HBV, n (\%) & $\mathrm{n} / \mathrm{a}$ & $74(100)$ & $23(26.7)$ & $13(16.5)$ & \\
\hline $\mathrm{EtOH}, \mathrm{n}(\%)$ & $\mathrm{n} / \mathrm{a}$ & $0(0)$ & $7(8.1)$ & $10(12.7)$ & \\
\hline NASH, n (\%) & $\mathrm{n} / \mathrm{a}$ & $0(0)$ & $10(11.6)$ & $14(17.7)$ & \\
\hline Other, n (\%) & $\mathrm{n} / \mathrm{a}$ & $0(0)$ & $3(3.5)$ & $4(5.1)$ & \\
\hline \multicolumn{6}{|l|}{ Ethnicity } \\
\hline Caucasian, n (\%) & $33(75.0)$ & $8(10.8)$ & $49(57.0)$ & $50(63.3)$ & \\
\hline Chinese, n (\%) & $6(13.6)$ & $48(64.9)$ & $12(14.0)$ & $12(15.2)$ & \\
\hline Middle eastern, $\mathrm{n}(\%)$ & $\mathrm{I}(2.3)$ & $9(12.2)$ & $20(23.3)$ & $9(11.4)$ & $<0.0001$ \\
\hline Indian, n (\%) & $4(9.1)$ & $5(6.8)$ & $3(3.5)$ & $3(3.8)$ & \\
\hline African, n (\%) & $0(0)$ & $2(2.7)$ & $\mathrm{I}(\mathrm{I} .2)$ & $3(3.8)$ & \\
\hline Polynesian, n (\%) & $0(0)$ & $2(2.7)$ & $\mathrm{I}(\mathrm{I} .2)$ & $2(2.5)$ & \\
\hline Diabetics, n (\%) & $0(0)$ & $10(\mid 3.5)$ & $29(33.7)$ & $30(38.0)$ & $<0.0001$ \\
\hline Bilirubin, mean \pm SD & $13.8(5.4)$ & | $3.5(8.4)$ & $21.2(14.5)$ & $22.0(24.0)$ & $<0.0001$ \\
\hline Albumin, mean \pm SD & $43.6(1.8)$ & $43.6(3.0)$ & $40.5(5.3)$ & $36.6(6.7)$ & $<0.000$ I \\
\hline$A L T$, mean $\pm S D$ & $30.8(10.9)$ & $41.5(38.5)$ & $65.3(61.5)$ & $86.9(89.4)$ & $<0.0001$ \\
\hline AST, mean \pm SD & $28.9(7.3)$ & $40.6(13.4)$ & $75.0(58.2)$ & $111.8(101.3)$ & $<0.0001$ \\
\hline PLT, mean \pm SD & $231.6(52.2)$ & $227.3(52.6)$ & $131.6(66.0)$ & $126.6(64.0)$ & $<0.0001$ \\
\hline AFP $(I U / m L)$, mean \pm SD & $\mathrm{n} / \mathrm{a}$ & $2.6(1.0)$ & $6.5(12.3)$ & $1869.6(10572.0)$ & $<0.0001$ \\
\hline$B C L C$ staging, $0 / A / B / C / D$ & $\mathrm{n} / \mathrm{a}$ & $\mathrm{n} / \mathrm{a}$ & $\mathrm{n} / \mathrm{a}$ & $4 / 29 / 30 / 13 / 3$ & \\
\hline Child-Pugh score, $A / B / C / n / a$ & $\mathrm{n} / \mathrm{a}$ & $\mathrm{n} / \mathrm{a}$ & $78 / 6 / 2 / 0$ & $50 / 13 / 7 / 9$ & \\
\hline Size of largest lesion, mean \pm SD & $\mathrm{n} / \mathrm{a}$ & $\mathrm{n} / \mathrm{a}$ & $\mathrm{n} / \mathrm{a}$ & $4.5(3.9)$ & \\
\hline Number of lesions, mean \pm SD & $\mathrm{n} / \mathrm{a}$ & $\mathrm{n} / \mathrm{a}$ & $\mathrm{n} / \mathrm{a}$ & $2.5(2.6)$ & \\
\hline Metastasis, Y/N & $\mathrm{n} / \mathrm{a}$ & $\mathrm{n} / \mathrm{a}$ & $\mathrm{n} / \mathrm{a}$ & $6 / 73$ & \\
\hline Portal vein invasion, $\mathbf{Y} / \mathbf{N}$ & $\mathrm{n} / \mathrm{a}$ & $\mathrm{n} / \mathrm{a}$ & $\mathrm{n} / \mathrm{a}$ & $11 / 68$ & \\
\hline
\end{tabular}

Notes: Results are expressed as mean (standard deviation) or frequency (percentage); P values were calculated using Kruskal-Wallis test with Dunn's multiple comparisons or a chi-square test.

Abbreviations: HCC, hepatocellular carcinoma; BMI, body mass index; HCV, hepatitis C virus; HBV, hepatitis B virus; EtOH, alcoholic liver disease; NASH, non-alcoholic steatohepatitis; ALT, alanine transaminase; AST, aspartate transaminase; PLT, platelet count; AFP, alpha-fetoprotein; BCLC, Barcelona Clinic Liver Cancer.

plates were analyzed in a VersaMax ELISA microplate reader at $450 \mathrm{~nm}$ with $650 \mathrm{~nm}$ as reference.

PRO-C3 was assessed in EDTA plasma samples for comparison to PC3X. The PRO-C3 competitive ELISA is a well-characterized assay based on a monoclonal antibody specific towards the $\mathrm{N}$-proteinase cleavage site of the N-terminal pro-peptide of type III collagen manufactured by Nordic Bioscience (Herlev, Denmark) and performed according to the manufacturer's specifications. ${ }^{30}$

\section{Statistical Analyses}

Characteristics of the patient groups are presented as frequency (percentage) for categorical variables and mean (standard deviation) for continuous variables. Statistical differences for categorical variables were assessed using chi-square tests whereas differences for continuous variables were evaluated using the Kruskal-Wallis test. Differences between biomarker levels in the different patient groups were assessed using the Kruskal-Wallis test adjusted for Dunn's multiple comparisons test. Pearson's correlation analysis was performed to describe the relationship between PC3X and PRO-C3 levels. The diagnostic power of the biomarkers was investigated by the area under the receiver operating characteristics (AUROC) curve and calculated using the method of Delong et al. ${ }^{31}$ The association between biomarker levels 
and clinical variables was assessed by multiple regression analysis using the enter method. Kaplan-Meier (KM) survival curves were used to analyze PFS and OS and a Log rank test was used to determine differences between KM curves. A Cox proportional-hazards regression model was used to calculate the hazard ratios (HR) with $95 \%$ CI for prediction of OS and PFS for the biomarkers and other clinical covariates: age, gender, BMI, Child-Pugh score, number of lesions, maximal tumor size and presence/ absence of portal vein invasion. Multivariate Cox proportional-hazards regression was used to assess the independent predictive value of PC3X and AFP adjusted for the above mentioned clinical variables. For statistical purposes, PC3X and PRO-C3 levels under the 75th percentile cut-point were used as a reference to calculate the HR for patients with levels above the 75 th percentile, which was based on the data distribution and previous studies. ${ }^{27,28}$ AFP levels under $20 \mathrm{IU} / \mathrm{mL}$ were used as a reference to calculate the HR for patients with elevated AFP levels. ${ }^{32}$ Sample size calculation was performed to calculate the adequate sample size for comparing $\mathrm{PC} 3 \mathrm{X}$ biomarker levels in patients with HCC to PC3X levels in patients with cirrhosis (alpha: 0.05, power: 0.8, difference of means: 7, standard deviation (SD): 14), resulting in a calculated sample size of 64 patients in each group. Another sample size calculation was performed to calculate the adequate sample size for conducting the survival analysis of PC 3X (alpha: 0.05, power: 0.8, survival group 0 and 1: 0.70 and 0.35 , ratio of sample sizes in group 1/ group 2: 4), resulting in a calculated sample size of 69 patients in total.

Statistical analyses were performed using MedCalc (v16.8.4) and Graphpad Prism (v7.01) (GraphPad Software, CA, USA). A $P$ value $<0.05$ was considered statistically significant.

\section{Results}

\section{Patient Characteristics}

The clinical characteristics of the patients with HCC, cirrhosis, non-cirrhotic HBV infection and healthy controls are summarized in Table 1. Some differences were observed between the groups and minor differences were seen according to age. Patients with cirrhosis/HCC had a greater BMI compared to the healthy controls and non-cirrhotic HBV infected patients. Most of the patients were males, but no significant difference was observed between the different groups of patients. No differences were seen in underlying etiology when comparing patients with cirrhosis and HCC. When evaluating ethnicity, the majority of patients in the non-cirrhotic HBV infected group were Chinese whereas most of the patients in the other groups were Caucasian. When assessing liver parameters, statistically significant differences were found in diabetes status, and levels of bilirubin, albumin, ALT, AST, PLT and AFP. Most of the HCC patients had Child-Pugh A disease and stage A or B according to BCLC staging.

\section{Plasma PC3X, PRO-C3 and AFP Levels Were Elevated in Patients with HCC}

PC3X, PRO-C3 and AFP were measured in healthy controls and patients with non-cirrhotic $\mathrm{HBV}$ infection, cirrhosis and $\mathrm{HCC}$ at the time of diagnosis, prior to the initiation of treatment (Figure 2A-C). PC3X, PRO-C3 and AFP levels were significantly elevated in $\mathrm{HCC}$ patients compared to those with cirrhosis (PC3X: $p=0.0002$, PRO-C $3: p=0.0016$, AFP: $p<0.0001)$, non-cirrhotic HBV infection $(p<0.0001)$ and healthy controls (PC3X and PRO-C3: $p<0.0001$, AFP: $\mathrm{N} / \mathrm{A}$ ). Of note, $58 \%$ of the HCC patients had normal AFP levels $(<20 \mathrm{IU} / \mathrm{mL})$. PRO-C3 was significantly higher in patients with non-cirrhotic $\mathrm{HBV}$ infection compared to healthy controls $(p=0.040)$, whereas PC3X was not $(p>0.999)$. In addition, the level of PC3X, PRO-C3 and AFP was significantly elevated in cirrhosis compared to patients with non-cirrhotic HBV infection (PC3X: $p=0.0013$, PRO-C3: $p<0.0001$, AFP: $p=0.018$ ).

Next, the biomarker levels in cirrhosis and HCC patients were evaluated according to Child-Pugh score (Figure 2D-F). Plasma PC3X and PRO-C3 were significantly higher in ChildPugh C compared to Child-Pugh A (PC3X: $p=0.034$, PRO-C3 $: p=0.035)$, whereas no significant difference was observed in AFP ( $p>0.999)$. When biomarker levels in the HCC patients were evaluated according to BCLC staging, no significant differences between stages were observed in either PC3X, PRO-C3 or AFP (data not shown).

\section{Association Between PC3X and PRO-C3}

As PC3X and PRO-C3 reflect similar biology, we investigated the association between PC3X and PRO-C3 in patients without cirrhosis (healthy controls and patients with noncirrhotic HBV infection) and with cirrhosis (cirrhosis and HCC patients). PC $3 \mathrm{X}$ and $\mathrm{PRO}-\mathrm{C} 3$ did not correlate in healthy controls and patients with non-cirrhotic HBV infection ( $\mathrm{r}=0.06, p=0.506)$ (Figure $3 \mathrm{~A})$, whereas the two markers significantly correlated in patients with cirrhosis and HCC $(\mathrm{r}=0.53, p<0.0001)$ (Figure 3B). 

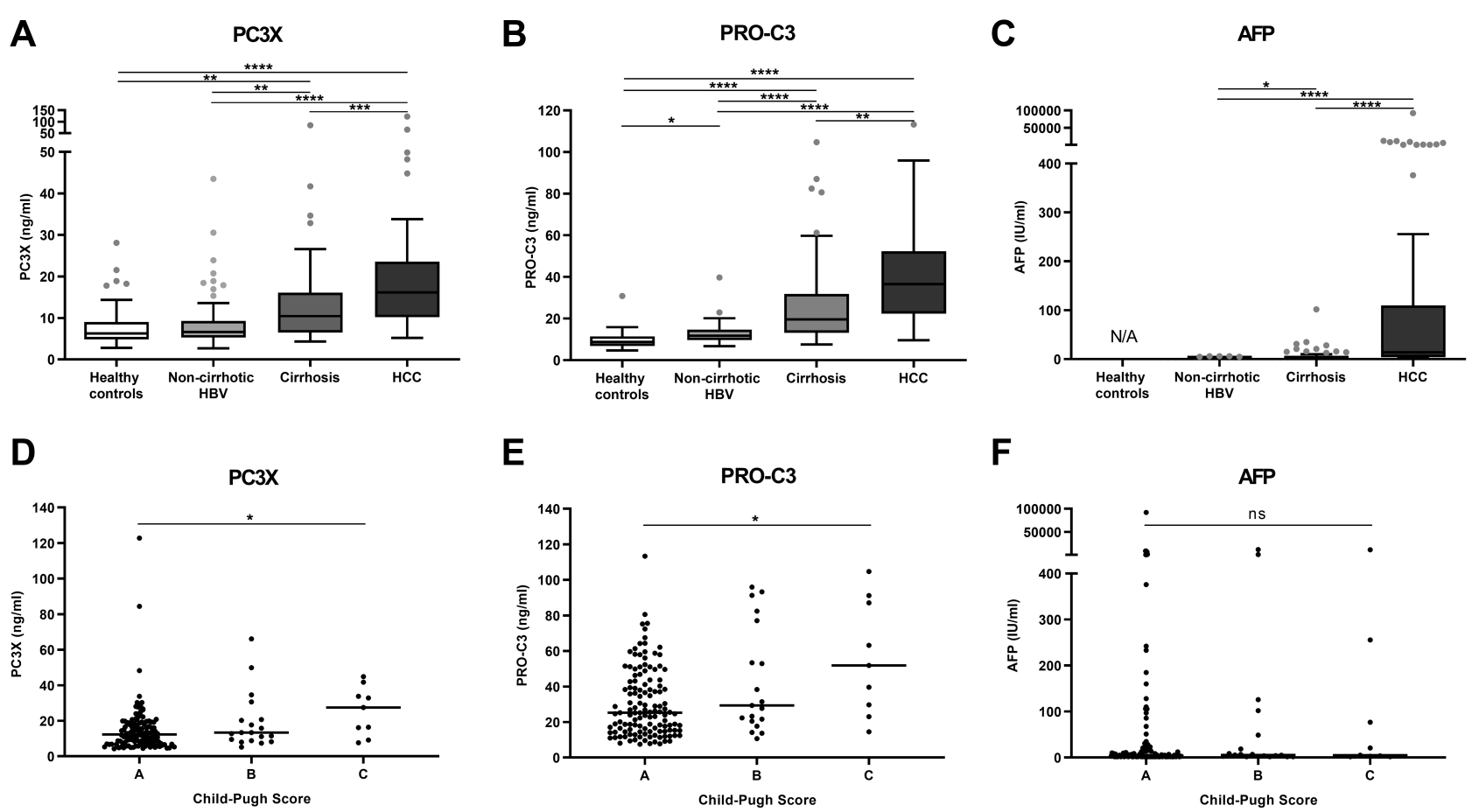

Figure 2 Evaluation of PC3X, PRO-C3 and AFP in healthy controls and in patients with non-cirrhotic HBV infection, cirrhosis and hepatocellular carcinoma (HCC). PC3X (A), PROC3 (B) and AFP levels $(C)$ in healthy controls $(n=44)$ and in patients with non-cirrhotic HBV infection ( $n=74)$, cirrhosis $(n=86)$ and HCC $(n=79)$. Data are presented as Tukey box plots. PC3X (D), PRO-C3 (E) and AFP (F) levels in cirrhosis and HCC patients separated by Child-Pugh score A $(n=128), B(n=19)$ and C ( $=9)$. The black horizontal lines represent the median value. Statistical differences were analyzed using the Kruskal-Wallis test adjusted for Dunn's multiple comparisons test $(\mathbf{A}-\mathbf{F})$. ${ }^{*} p<0.05, * * p<0.01, * * * k<0.00$ I, $* * * * p<0.000$ I. Abbreviation: ns, non-significant.

Similar Diagnostic Performance of PC3X, PRO-C3 and AFP

To evaluate the capability of separating patients with early HCC (BCLC stage 0 and A) from cirrhosis, the AUROC was

A

Healthy controls and non-cirrhotic HBV

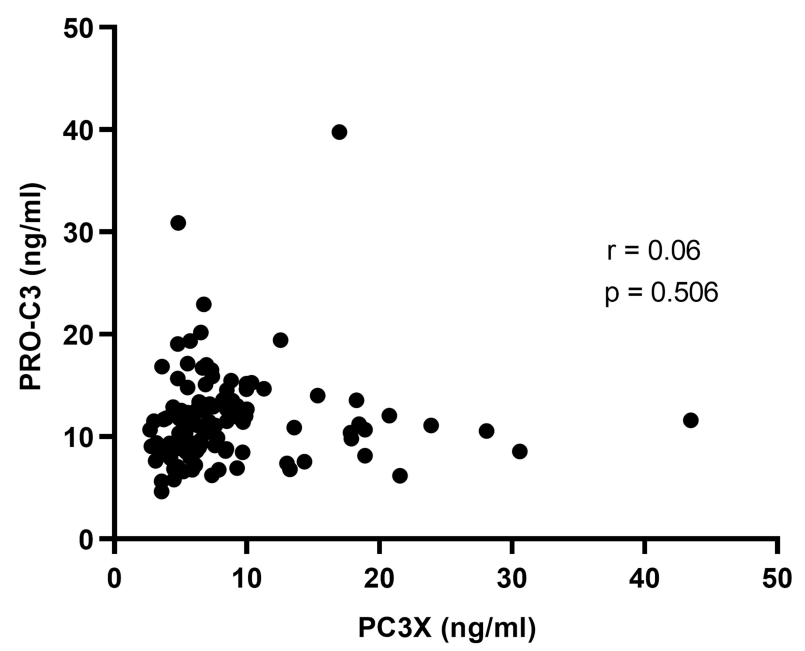

used to assess the diagnostic performance of PC3X, PRO-C3 and AFP, individually. PC3X, PRO-C3 and AFP were able to separate patients with early $\mathrm{HCC}$ from cirrhosis without $\mathrm{HCC}$ with an AUROC of 0.70, 0.68 and 0.75, with sensitivities of

B

\section{Cirrhosis and HCC}

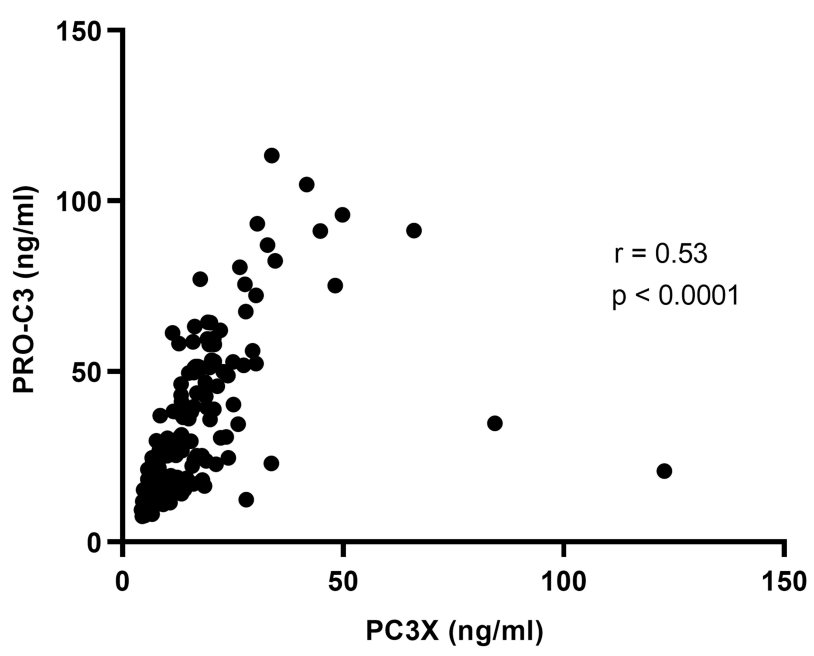

Figure 3 Correlation between PC3X and PRO-C3 levels. Pearson's correlation analysis was performed to describe the relationship between PC3X and PRO-C3 levels in EDTA plasma from healthy controls and patients with non-cirrhotic HBV infection (A), and in cirrhosis and HCC patients (B). 
$45.5 \%, 69.7 \%$ and $33.3 \%$ and specificities of $87.2 \%, 72.1 \%$ and $93.0 \%$, respectively (Table 2) (see Table 1 in Supplemental Digital Content 3 , which shows the ROC curves). Next, we evaluated PC3X and PRO-C3's diagnostic potential in patients with normal AFP $(<20 \mathrm{IU} / \mathrm{mL})$ and detected AUROCs of 0.72 and 0.68 for separating early HCC from cirrhosis.

\section{Association of Biomarker Levels in HCC with Clinical Variables}

We evaluated the correlation between PC3X, PRO-C3 and AFP levels in HCC patients with the liver function markers albumin, ALT, AST, bilirubin and PLT (see Table 1 in Supplemental Digital Content 4). PC3X correlated weakly to AFP ( $\mathrm{r}=0.25, \mathrm{p}=0.026)$, ALT $(\mathrm{r}=0.37, \mathrm{p}=0.0009)$, AST $(\mathrm{r}=0.38, \mathrm{p}=0.0006)$ and age $(\mathrm{r}=-0.41, \mathrm{p}=0.0001)$ and strongly to PRO-C3 ( $\mathrm{r}=0.72, \mathrm{p}<0.0001)$. A weak correlation was also observed between PRO-C3 and AFP ( $r=0.30, p=0.007)$, age $(\mathrm{r}=-0.35, \mathrm{p}=0.002)$, albumin $(\mathrm{r}=-0.26, \mathrm{p}=0.022)$, ALT $(\mathrm{r}=0.38, \mathrm{p}=0.0006)$ and AST $(\mathrm{r}=0.48, \mathrm{p}<0.0001)$. AFP correlated weakly to ALT $(r=0.29, p=0.009)$ and AST $(r=0.29$, $\mathrm{p}=0.009$ ) in addition to PC $3 \mathrm{X}$ and PRO-C3.

Next, we examined the association between PC3X, PRO$\mathrm{C} 3$ and AFP levels in the HCC patients with the tumor-related clinical variables Child-Pugh score, size of largest lesion, number of lesions, existence of metastases and existence of portal vein invasion using a multiple regression analysis. The only clinical co-variates that contributed significantly to PC 3X were the number of lesions ( $p=0.001$ ), whereas the presence of portal vein invasion contributed to AFP $(p=0.019)$ and no associations were found between PRO-C 3 and these clinical variables (see Table 2 in Supplemental Digital Content 4, which shows the multiple regression analysis).

\section{Prognostic Performance of PC $3 \mathrm{X}$, PRO-C3 and AFP in Patients with HCC}

Next, we evaluated the prognostic potential of PC3X, PRO-C3 and AFP in HCC by Kaplan-Meier curves and Cox proportional-hazard models. The median PFS for HCC patients was 270 days (range, 30-3960 days) while the median OS was 1080 days (range, 30-6120 days). Using the Kaplan-Meier method, we assessed the association between biomarker levels and survival (Figure 4). High PC3X levels ( $>75$ th percentile) were associated with shorter PFS $(p=0.024)$ and OS $(p=0.011)$, compared to lower levels ( $\leq 75$ th percentile) (Figure $4 \mathrm{~A}$ and D). The median PFS and OS were 180 and 540 days in biomarker high, versus 300 and 1530 days in biomarker low patients, for PFS and OS, respectively. High levels ( $>75$ th percentile) of the biomarker PRO-C3 were not associated with shorter PFS ( $p=0.054)$ or OS ( $p=0.383)$ compared to lower levels ( $\leq 75$ th percentile) (Figure $4 \mathrm{~B}$ and E). High AFP $(>20 \mathrm{IU} / \mathrm{mL}$ ) was significantly associated with poor PFS ( $p=0.035)$ and $\mathrm{OS}(p=0.001)$ compared to lower levels $(\leq 20 \mathrm{IU} / \mathrm{mL}$ ) (Figure $4 \mathrm{C}$ and $\mathrm{F}$ ). When combining PC3X and AFP, high PC $3 \mathrm{X}$ and high AFP were associated with poor PFS $(\mathrm{p}=0.003)$ and OS $(\mathrm{p}<0.0001)$ compared to low levels (Figure 5). In detail, the median PFS and OS were 120 and 240 days for patients with high PC $3 \mathrm{X}$ and high AFP levels, 255 and 960 days for patients with either high PC3X or high AFP, and 390 and 1920 days for patients with both low PC3X and low AFP, respectively.

The ability of PC3X to predict PFS and OS in HCC patients was then evaluated by Cox proportional-hazard models (Table 3). The patients with high PC3X levels ( $>75$ th percentile) had significantly poorer PFS and OS compared to those with lower PC3X levels (PFS:

Table 2 Discriminative Performance of Biomarkers in HCC with BCLC O/A Vs Cirrhosis

\begin{tabular}{|c|c|c|c|c|c|c|c|c|}
\hline $\begin{array}{l}\text { HCC vs } \\
\text { Cirrhosis }\end{array}$ & $\begin{array}{l}\text { Cutoff Value } \\
\text { (ng/mL) }\end{array}$ & $\begin{array}{l}\text { Sensitivity } \\
\text { (\%) }\end{array}$ & $\begin{array}{l}\text { Specificity } \\
\text { (\%) }\end{array}$ & PPV & NPV & +LHR & $\begin{array}{l}\text { AUROC } \\
(95 \% \mathrm{CI})\end{array}$ & P-value \\
\hline $\mathrm{PC} 3 \mathrm{X}$ & 19.2 & 45.5 & 87.2 & 57.7 & 80.6 & 3.55 & $0.70(0.61-0.78)$ & 0.0002 \\
\hline PRO-C3 & 28.1 & 69.7 & 72.1 & 48.9 & 86.1 & 2.50 & $0.68(0.59-0.76)$ & 0.001 \\
\hline AFP & 20.0 & 33.3 & 93.0 & 64.6 & 78.4 & 4.78 & $0.75(0.67-0.83)$ & $<0.0001$ \\
\hline \multicolumn{9}{|c|}{ HCC vs cirrhotic patients with AFP $<20 \mathrm{IU} / \mathrm{mL}$} \\
\hline PC3X & 19.2 & 54.6 & 90.0 & 60.0 & 87.8 & 5.45 & $0.72(0.62-0.81)$ & 0.0009 \\
\hline PRO-C3 & 29.0 & 63.6 & 77.5 & 43.8 & 88.6 & 2.83 & $0.68(0.58-0.77)$ & 0.010 \\
\hline
\end{tabular}

Notes: AUROC and $p$ values were calculated using the method of Delong et al; ${ }^{31}$ The cutoff value for PC $3 \mathrm{X}$ and PRO-C3 was obtained from AUROC, whereas $20 \mathrm{Ul} / \mathrm{mL}$ for AFP is an indication of elevated levels. ${ }^{32}$

Abbreviations: HCC, hepatocellular carcinoma; AFP, alpha-fetoprotein; PPV, positive predictive value; NPV, negative predictive value; LHR, likelihood ratio; AUROC, area under the receiver operating characteristics. 

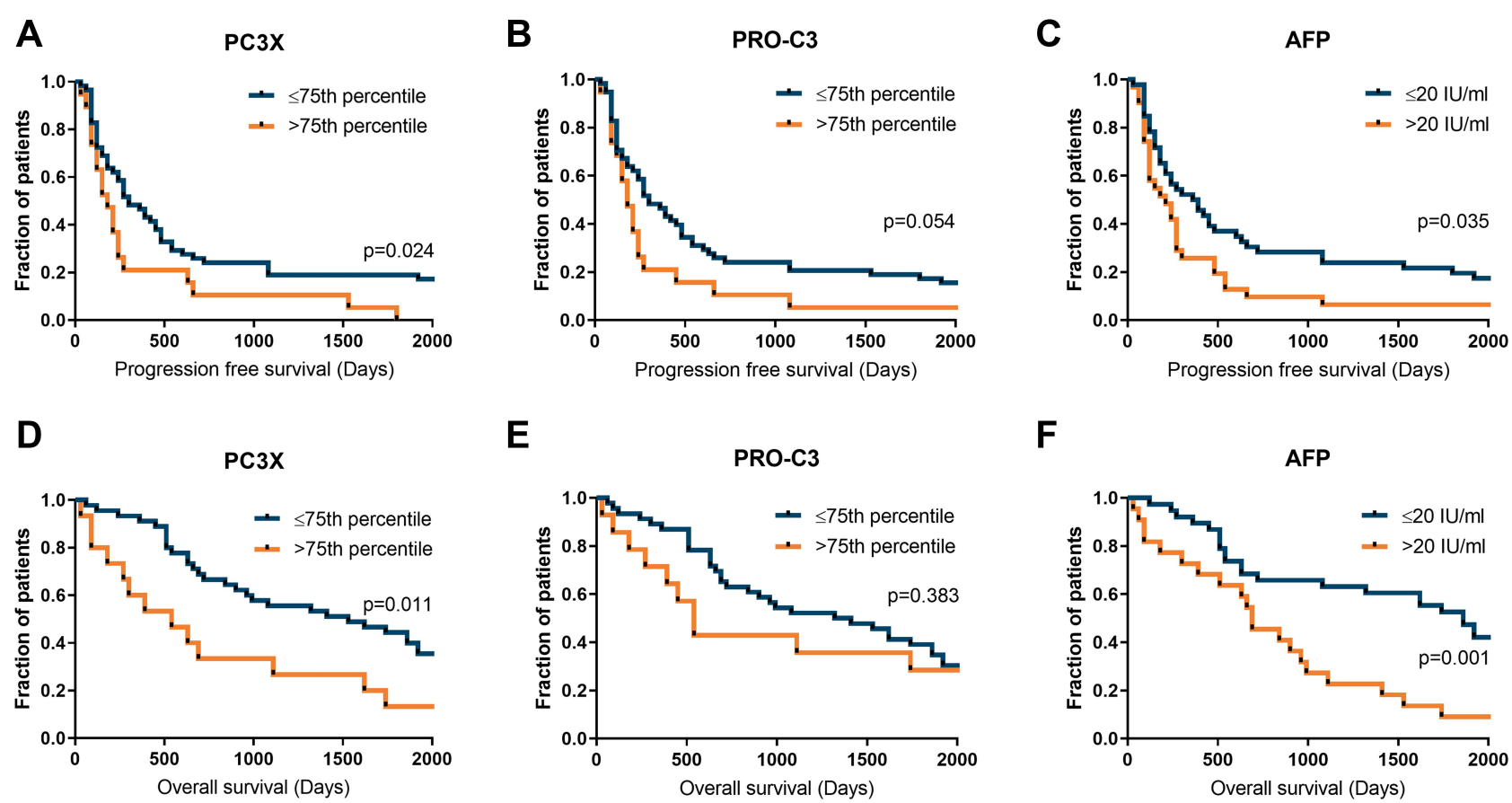

Figure 4 Kaplan-Meier analysis of progression-free survival and overall survival in hepatocellular carcinoma patients. Progression-free survival (A-C) and overall survival (D-F) for hepatocellular carcinoma patients with biomarker levels above the 75th percentile vs below for PC3X (A and D) and PRO-C3 (B and E), while for AFP it is above $20 \mathrm{Ul} / \mathrm{mL}$ vs below $(\mathbf{C}$ and $\mathbf{F}$ ). A Log rank test was used to determine differences between the curves. A $p$-value of $p<0.05$ was considered significant.
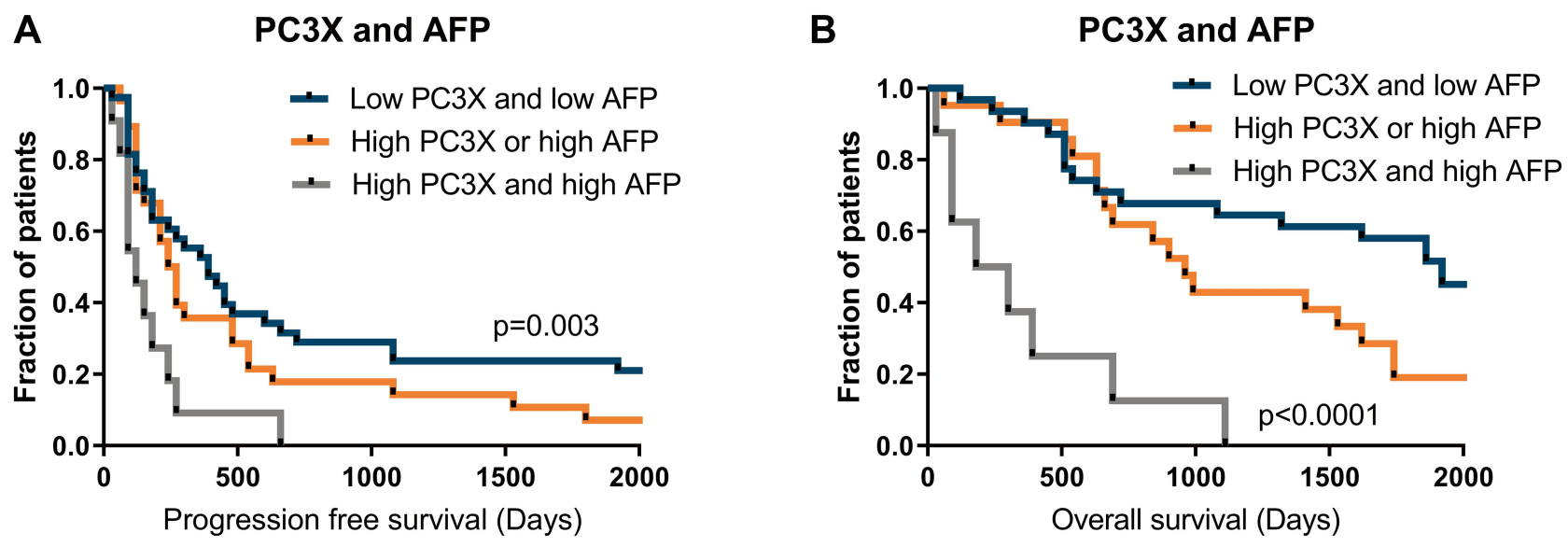

Figure 5 Progression-free survival and overall survival by Kaplan-Meier analysis, comparing the subgroups of patients with low or high PC $3 X$ and AFP levels in hepatocellular carcinoma. Progression-free survival (A) and overall survival (B) for hepatocellular carcinoma patients with either low PC3X and low AFP, high PC $3 X$ or high AFP, or high PC3X and high AFP. A Log rank test was used to determine differences between the curves. A p-value of $p<0.05$ was considered significant.

$\mathrm{HR}=1.80,95 \% \mathrm{CI}=1.05-3.08, p=0.032$ and $\mathrm{OS}: \mathrm{HR}=2.12$, 95\% $\mathrm{CI}=1.10-4.05, \quad p=0.024)$. A similar trend was observed when PC3X was evaluated on a continuous univariate scale; $\mathrm{PC} 3 \mathrm{X}$ was predictive of poor $\mathrm{PFS}(\mathrm{HR}=1.02$, 95\% $\mathrm{CI}=1.01-1.04, p=0.007)$ and borderline predictive of poor $\mathrm{OS}(\mathrm{HR}=1.03,95 \% \mathrm{CI}=1.00-1.06, p=0.054)$.

Comparable results were observed for AFP, high levels $(>20 \mathrm{IU} / \mathrm{mL})$ were predictive of poor PFS $(\mathrm{HR}=1.70,95 \%$ $\mathrm{CI}=1.05-2.76, \quad p=0.031) \quad$ and $\quad \mathrm{OS} \quad(\mathrm{HR}=2.55, \quad 95 \%$
$\mathrm{CI}=1.38-4.69, p=0.003$ ), and on a continuous univariate scale, AFP was predictive of poor OS $(\mathrm{HR}=1.00,95 \%$ $\mathrm{CI}=1.00-1.00, p=0.030)$. In contrast, high PRO-C3 $(>75$ th percentile) was not predictive of poor $\mathrm{PFS}(\mathrm{HR}=1.19,95 \%$ $\mathrm{CI}=0.99-1.42, \quad p=0.059) \quad$ or $\quad \mathrm{OS} \quad(\mathrm{HR}=1.12, \quad 95 \%$ $\mathrm{CI}=0.89-1.41, p=0.324)$. When combining PC3X and AFP, high PC3X and high AFP were predictive of PFS ( $\mathrm{HR}=2.66$, 95\% $\mathrm{CI}=1.37-5-18, p=0.004)$ and $\mathrm{OS}(\mathrm{HR}=5.86,95 \%$ $\mathrm{CI}=2.57-13.37, p<0.0001)$ compared to low levels. 
Table 3 Association Between Biomarker Levels, Clinical Covariates and Outcome for HCC Patients

\begin{tabular}{|c|c|c|c|c|c|c|c|}
\hline Variables & & \multicolumn{3}{|c|}{$\begin{array}{l}\text { Progression-Free } \\
\text { Survival }\end{array}$} & \multicolumn{3}{|c|}{ Overall Survival } \\
\hline \multicolumn{2}{|l|}{ Univariate Analysis } & HR & $95 \% \mathrm{Cl}$ & P-value & HR & $95 \% \mathrm{Cl}$ & P-value \\
\hline Age & Continuous & 1.01 & $0.99-1.03$ & 0.332 & 1.01 & $0.99-1.04$ & 0.280 \\
\hline Gender (male) & Male vs female & 0.78 & $0.36-1.7 \mid$ & 0.533 & 1.04 & $0.4 I-2.65$ & 0.932 \\
\hline BMI & Continuous & 1.01 & $0.97-1.05$ & 0.672 & 0.99 & $0.94-1.04$ & 0.634 \\
\hline Child-Pugh score & $B / C$ vs $A$ & 2.39 & $1.37-4.19$ & 0.002 & 5.06 & $2.58-9.93$ & $<0.0001$ \\
\hline Size of largest lesion & Continuous & 1.08 & $1.02-1.14$ & 0.007 & 1.14 & $1.07-1.22$ & 0.0001 \\
\hline Number of lesions & Continuous & 1.18 & $1.08-1.29$ & 0.0003 & 1.41 & $1.22-1.63$ & $<0.0001$ \\
\hline Portal vein invasion & Yes vs no & 2.57 & $1.25-5.11$ & 0.010 & 3.53 & $|.52-8.2|$ & 0.003 \\
\hline \multirow[t]{2}{*}{$\mathrm{PC} 3 \mathrm{X}$} & Continuous & 1.02 & $1.01-1.04$ & 0.007 & 1.03 & $1.00-1.06$ & 0.054 \\
\hline & $\begin{array}{l}\text { High }(23.9-122.8 \mathrm{ng} / \mathrm{mL}, \mathrm{Q} 4) \text { vs } \\
\text { low }(5.2-23.5 \mathrm{ng} / \mathrm{mL}, \mathrm{Q} \text { I-Q3) }\end{array}$ & 1.80 & $1.05-3.08$ & 0.032 & 2.12 & I. $10-4.05$ & 0.024 \\
\hline \multirow[t]{2}{*}{ PRO-C3 } & Continuous & 1.01 & $1.00-1.03$ & 0.020 & 1.01 & $0.99-1.03$ & 0.052 \\
\hline & $\begin{array}{l}\text { High }(52.3-\mathrm{I} \text { I } 3.3 \mathrm{ng} / \mathrm{mL}, \mathrm{Q} 4) \text { vs } \\
\text { low }(5.3-51.8 \mathrm{ng} / \mathrm{mL}, \mathrm{Q} \text { I-Q3) }\end{array}$ & 1.19 & $0.99-1.42$ & 0.059 & 1.12 & $0.89-|.4|$ & 0.324 \\
\hline \multirow[t]{2}{*}{ AFP } & Continuous & 1.00 & $1.00-1.00$ & 0.171 & 1.00 & $1.00-1.00$ & 0.030 \\
\hline & High vs low ( $\geq 20$ vs $<20 \mathrm{IU} / \mathrm{mL}$ ) & 1.70 & $1.05-2.76$ & 0.031 & 2.55 & $1.38-4.69$ & 0.003 \\
\hline $\mathrm{PC} 3 \mathrm{X}$ and AFP & $\begin{array}{l}\text { High PC } 3 X \text { and high AFP vs low } \\
\text { PC } 3 X \text { and/or low AFP }\end{array}$ & 2.66 & $1.37-5.18$ & 0.004 & 5.86 & $2.57-13.37$ & $<0.000$ I \\
\hline \multicolumn{2}{|l|}{ Multivariate Analysis } & HR & $95 \% \mathrm{Cl}$ & P-value & HR & $95 \% \mathrm{Cl}$ & P-value \\
\hline \multicolumn{8}{|c|}{ Adjusted for age, gender and BMI } \\
\hline PC3X & High vs low (Q4 vs QI-Q3) & 1.88 & $1.07-3.31$ & 0.028 & 2.54 & $1.27-5.08$ & 0.008 \\
\hline AFP & High vs low ( $\geq 20$ vs $<20 \mathrm{IU} / \mathrm{mL}$ ) & 1.64 & $0.99-2.73$ & 0.054 & 2.50 & $1.31-4.75$ & 0.005 \\
\hline PC $3 \mathrm{X}$ and AFP & $\begin{array}{l}\text { High PC } 3 X \text { and high AFP vs low } \\
\text { PC } 3 X \text { and/or low AFP }\end{array}$ & 2.81 & $1.38-5.74$ & 0.004 & 6.35 & $2.66-15.15$ & $<0.0001$ \\
\hline \multicolumn{8}{|c|}{ Adjusted for Child-Pugh score } \\
\hline $\mathrm{PC} 3 \mathrm{X}$ & High vs low (Q4 vs QI-Q3) & 1.53 & $0.87-2.67$ & 0.140 & 2.23 & I. $12-4.47$ & 0.023 \\
\hline AFP & High vs low ( $\geq 20$ vs $<20 \mathrm{IU} / \mathrm{mL}$ ) & 1.96 & $1.17-3.29$ & 0.011 & 4.53 & $2.24-9.19$ & $<0.0001$ \\
\hline $\mathrm{PC} 3 \mathrm{X}$ and AFP & $\begin{array}{l}\text { High PC } 3 X \text { and high AFP vs low } \\
\text { PC } 3 X \text { and/or low AFP }\end{array}$ & 2.68 & $1.36-5.28$ & 0.004 & 8.17 & $3.31-20.13$ & $<0.000$ I \\
\hline \multicolumn{8}{|c|}{$\begin{array}{l}\text { Adjusted for size of largest lesion, number of } \\
\text { lesions and presence of portal vein invasion }\end{array}$} \\
\hline $\mathrm{PC} 3 \mathrm{X}$ & High vs low (Q4 vs QI-Q3) & 1.43 & $0.79-2.59$ & $0.24 I$ & 1.47 & $0.69-3.13$ & 0.317 \\
\hline AFP & High vs low ( $\geq 20$ vs $<20 \mathrm{IU} / \mathrm{mL}$ ) & 1.65 & $0.98-2.76$ & 0.059 & 2.26 & I. $12-4.56$ & 0.023 \\
\hline PC $3 \mathrm{X}$ and AFP & $\begin{array}{l}\text { High PC } 3 \text { X and high AFP vs low } \\
\text { PC } 3 X \text { and/or low AFP }\end{array}$ & 2.01 & $0.99-4.07$ & 0.053 & 4.40 & $1.77-10.89$ & 0.001 \\
\hline PC $3 \mathrm{X}$ adjusted for AFP & High vs low (Q4 vs QI-Q3) & 1.74 & $1.01-2.98$ & 0.045 & 2.21 & $1.15-4.27$ & 0.018 \\
\hline
\end{tabular}

Notes: Hazard ratios were calculated by univariate and multivariate Cox proportional-hazard analysis; By univariate analysis, PC3X and PRO-C3 were analyzed on both a continuous scale and divided into quartiles with the lower levels (QI-Q3) used as a reference to calculate the HR for patients in the upper quartile (Q4); The covariates were analyzed on a continuous scale, and Child-Pugh score and AFP were furthermore analyzed on a binominal scale; By multivariable analysis, PC 3 X and AFP were adjusted as indicated in the text.

Abbreviations: AFP, alpha-fetoprotein; BMI, body mass index; HR, hazard ratio.

To determine the independent predictive value of high PC3X, multivariate Cox proportional-hazard analysis was conducted. When PC $3 \mathrm{X}$ was adjusted for the covariates age, gender and BMI, high PC3X was independently predictive of poor PFS and OS (PFS: $\mathrm{HR}=1.88,95 \%$ $\mathrm{CI}=1.07-3.31, \quad p=0.028 \quad$ and $\mathrm{OS}: \quad \mathrm{HR}=2.54, \quad 95 \%$ $\mathrm{CI}=1.27-5.08, p=0.008)$. PC3X was then adjusted for Child-Pugh score and the tumor-related variables size of 
largest lesion, number of lesions and presence of portal vein invasion because these factors are individually predictive of poor PFS and OS (Table 3). PC3X was independently predictive of poor OS when adjusted for Child-Pugh score $(\mathrm{HR}=2.23,95 \% \mathrm{CI}=1.12-4.47, p=0.023)$ but not PFS; PC3X remained not significant when adjusted for size of largest lesion, number of lesions and presence of portal vein invasion. On the other hand, high AFP was predictive of poor PFS and OS when adjusted for Child-Pugh score (PFS: $\mathrm{HR}=1.96,95 \% \mathrm{CI}=1.17-3.29, p=0.011$ and $\mathrm{OS}: \mathrm{HR}=4.53$, $95 \% \mathrm{CI}=2.24-9.19, p<0.0001)$ and size of largest lesion, number of lesions and presence of portal vein invasion (PFS: $\mathrm{HR}=1.65,95 \% \mathrm{CI}=0.98-2.76, p=0.059$ and $\mathrm{OS}$ : $\mathrm{HR}=2.26,95 \% \mathrm{CI}=1.12-4.56, p=0.023$ ), though only borderline statistically significant of PFS. High AFP was predictive of poor OS when adjusted for age, gender and BMI $(\mathrm{HR}=2.50,95 \% \mathrm{CI}=1.31-4.75, p=0.005)$, but not of poor PFS. Interestingly, PC3X was independently predictive of poor PFS and OS when it was adjusted for AFP (PFS: $\mathrm{HR}=1.74,95 \% \mathrm{CI}=1.01-2.98, p=0.045$ and $\mathrm{OS}: \mathrm{HR}=2.21$, $95 \% \mathrm{CI}=1.15-4.27, p=0.018)$. In addition, when high $\mathrm{PC} 3 \mathrm{X}$ and high AFP were combined, they were independently predictive of poor PFS and OS when adjusted for ChildPugh score (PFS: HR=2.68, 95\% CI=1.36-5.28, $p=0.004$ and $\mathrm{OS}: \mathrm{HR}=8.17,95 \% \mathrm{CI}=3.31-20.13, p<0.0001$ ), age, gender and $\mathrm{BMI}$ (PFS: $\mathrm{HR}=2.81,95 \% \mathrm{CI}=1.38-5.74$, $p=0.004$ and $\mathrm{OS}: \mathrm{HR}=6.35,95 \% \quad \mathrm{CI}=2.66-15.15$, $p<0.0001$ ), and when adjusted for size of largest lesion, number of lesions and presence of portal vein invasion (PFS: $\mathrm{HR}=2.01,95 \% \mathrm{CI}=0.99-4.07, p=0.053$ and $\mathrm{OS}$ : $\mathrm{HR}=4.20,95 \% \mathrm{CI}=1.66-10.62, p=0.003)$, though only borderline statistically significant for PFS (Table 3 ).

\section{Discussion}

We investigated a biomarker reflecting increased type III collagen deposition and cross-linking (PC3X) and evaluated its potential in $\mathrm{HCC}$ in comparison to $\mathrm{PRO}-\mathrm{C} 3$ and AFP. The main findings were that: 1) PC3X was significantly elevated in plasma from patients with HCC compared to those with non-cirrhotic HBV infection, cirrhosis, and healthy controls, 2) high levels of PC3X in HCC patients were associated with shorter PFS and OS, 3) $\mathrm{PC} 3 \mathrm{X}$ as a prognostic biomarker was superior to PROC3 and independent of AFP, and 4) PC3X and AFP when combined had additive prognostic value versus either alone. Thus, this is the first study to show that crosslinked type III collagen pro-peptides, a marker of the ECM has biomarker potential in primary liver cancer.
Fibrosis-associated myofibroblasts, collagen deposition and liver stiffness are key features of the hepatic premalignant environment. At the level of the cellular microenvironment, they play essential roles in HCC development and progression, suggesting that collagens could be an important source of biomarkers. ${ }^{11,33-35}$ We found cross-linked multimeric type III collagen pro-peptides (PC3X) in the circulation at higher levels in the cancer patients compared to those with other liver diseases and healthy controls. Similar findings were observed for the well-known liver fibrosis biomarker PRO-C3. However, whereas a significant difference in PRO-C3 was observed between controls and patients with non-cirrhotic $\mathrm{HBV}$ infection, no difference was seen in PC3X levels. In addition, when evaluating the correlation of PRO-C3 and PC3X in healthy and pathological conditions, the two markers were not coordinately altered. Whereas the correlation was pronounced in patients with cirrhosis and HCC, this was not the case in healthy controls and non-cirrhotic HBV infected patients. This suggests that late-stage fibrosis states (cirrhosis and HCC) are characterized by a more homogeneous composition of the ECM, and with regard to type III collagens, are more cross-linked. It also implies that as a biomarker for $\mathrm{HCC}, \mathrm{PC} 3 \mathrm{X}$ is likely to have superior performance to PRO-C3.

Cross-linking and matrix stiffness correlate with HCC risk and tumor progression. ${ }^{12,36}$ Furthermore, the enzymes LOXL2 and TG2 responsible for cross-linking have been shown to have prominent roles in $\mathrm{HCC}$ invasion and metastasis. ${ }^{15-17}$ Consistently, we found that high PC3X levels were predictive of poor PFS and OS, whereas high levels of PRO-C3 were not. This suggests that PC $3 \mathrm{X}$ has additional potential as a prognostic biomarker of cancer outcomes, and is superior to PRO-C3.

We found that high PC3X was predictive of poor PFS and OS when adjusted for age, gender and BMI, covariates that can affect collagen turnover. ${ }^{37}$ High PC3X was however not predictive for PFS when adjusted for Child-Pugh score. This is not surprising as the ChildPugh score is based on liver function parameters that are affected by the severity of fibrosis. ${ }^{38}$ We also found that PC3X was not predictive for PFS or OS when adjusted for size of largest lesion, number of lesions and presence of portal vein invasion. Again, LOXL2-mediated collagen cross-linking has been shown to act as invasion highways promoting both intrahepatic and extrahepatic metastasis implying that the degree of cross-linking of collagens associates with the number of lesions and with advanced disease. $^{15}$ 
Similar to other studies, we detected high AFP levels in HCC patients and high levels were associated with poor outcomes. ${ }^{39,40}$ However, $58 \%$ of cancer patients had AFP levels $(<20 \mathrm{IU} / \mathrm{mL})$ that would not usually prompt further investigation; the large difference between cirrhosis and HCC was driven by a subgroup with very high AFP levels secreted by the malignant hepatocytes. Since AFP secretion can vary widely between malignant hepatocytes, as a biomarker it has low sensitivity, a major limitation to its diagnostic use. Interestingly, and as would be expected, PC $3 \mathrm{X}$ as a matrix-derived biomarker had diagnostic value in the subgroup of HCC patients with low/normal AFP levels. Thus, though PC3X may not have superior diagnostic performance compared to AFP, PC3X does provide additional diagnostic value suggesting potential as a risk assessment marker. Moreover, high PC $3 \mathrm{X}$ was independently predictive of poor PFS and OS when adjusted for AFP supporting the argument that PC3X measures a pathologically distinct aspect of tumor biology as compared to tumor-derived AFP (see Figure 1 in Supplemental Digital Content 5). In addition, we detected improved prognostic potential when combining $\mathrm{PC} 3 \mathrm{X}$ and $\mathrm{AFP}$ emphasizing the importance of assessing ECM as well as tumor-cell properties in HCC.

In sum, PC 3X is a novel marker of ECM deposition and stiffness that is associated with HCC outcomes. We speculate that cross-linked type III collagen pro-peptides are released to the circulation from the hepatic premalignant environment in cirrhotic patients, and in increased levels from the tumor microenvironment. This is likely associated with the high activity of cancer-associated fibroblasts (CAFs) and cross-linking enzymes (see Figure 1 in Supplemental Digital Content 5) ${ }^{11,41}$ LOXL2 and TG2 are increasingly considered therapeutic targets to reduce matrix stiffness and attenuate cancer progression. Thus, PC3X may also have predictive potential in this setting. ${ }^{42,43}$

The limitations of this study include that it is a relatively small $\mathrm{HCC}$ cohort that comprises patients with both early- and late-stage disease, who were treated with different treatment regimens, thus impacting differentially on outcomes. Thus, larger studies are required to validate the biomarker potential of $\mathrm{PC} 3 \mathrm{X}$ in $\mathrm{HCC}$.

\section{Conclusion}

In conclusion, cross-linked multimeric type III collagen propeptides can be used as a biomarker of tissue stiffness in HCC and as we show, they measure a pathophysiologically distinct aspect of tumor biology than AFP. PC3X was higher in HCC compared to other liver diseases and healthy controls. In addition, high levels of PC3X in cancer were associated with shorter PFS and OS suggesting that this marker has prognostic potential.

\section{Abbreviations}

AFP, alpha-fetoprotein; ALT, alanine transaminase; AASLD, American Association for the Study of Liver Diseases; AUROC, area under the receiver operating characteristics; APASL, Asian Pacific Association for the Study of the Liver; AST, aspartate transaminase; BCLC, Barcelona Clinic Liver Cancer; BMI, body mass index; CAFs, cancerassociated fibroblasts; PC3X, cross-linked pro-peptides of type III collagen; EASL, European Association for the Study of the Liver; ECM, extracellular matrix; HR, hazard ratios; HBV, hepatitis B virus; HCC, hepatocellular carcinoma; HRP, horseradish peroxidase; KM, Kaplan-Meier; LOX, lysyl oxidase; LOXL, LOX-like; OS, overall survival; PLT, platelet count; PFS, progression-free survival; SD, standard deviation; TMB, tetramethylbenzidine; TACE, transarterial chemoembolization; TG2, transglutaminase 2.

\section{Data Sharing Statement}

The data obtained in the current study are included in this published article, available from the corresponding author or available from the indicated sources.

\section{Ethics Approval and Informed Consent}

The study was approved by the Human Ethics Committee of the Sydney West Area Health Service (HREC No.2002/12/ 4.9 (1564)) in compliance with the Helsinki Declaration. Written informed consent was obtained from all participants.

\section{Acknowledgments}

We would like to thank Emilie Albrecht Madsen for her help during PRO-C3 sample measurements.

\section{Funding}

The ECM biomarker development and assessment were supported by the Danish Research Foundation. M. Eslam, D. v. Poorten and J. George are supported by the Robert W. Storr Bequest to the Sydney Medical Foundation, University of Sydney; a National Health and Medical Research Council of Australia (NHMRC) Program Grant (APP1053206, APP1149976) and Project grants (APP1107178 and APP1108422). 


\section{Disclosure}

C. Jensen, S. Holm Nielsen, F. Genovese, M. J. Nielsen, M. A. Karsdal, D. J. Leeming and N. Willumsen are employed at Nordic Bioscience which is a company involved in discovery and development of biochemical biomarkers. M. A. Karsdal, F. Genovese and D. J. Leeming own stocks in Nordic Bioscience. The authors report no other conflicts of interest in this work.

\section{References}

1. International Agency for Research on Cancer. Global cancer observatory. Cancer today. 2020. Available from: http://gco.iarc.fr/. Global Cancer Observatory. http://gco.iarc.fr/. Accessed October 22, 2020.

2. Lee SS, Shin HS, Kim HJ, et al. Analysis of prognostic factors and 5 -year survival rate in patients with hepatocellular carcinoma: a single-center experience. Korean J Hepatol. 2012;18(1):48-55. doi:10.3350/kjhep.2012.18.1.48

3. Bray F, Ferlay J, Soerjomataram I, Siegel RL, Torre LA, Jemal A. Global cancer statistics 2018: GLOBOCAN estimates of incidence and mortality worldwide for 36 cancers in 185 countries. CA Cancer J Clin. 2018;68(6):394-424. doi:10.3322/caac.21492

4. Singal AG, Pillai A, Tiro J. Early detection, curative treatment, and survival rates for hepatocellular carcinoma surveillance in patients with cirrhosis: a meta-analysis. PLoS Med. 2014;11(4):e1001624. doi:10.1371/journal.pmed.1001624

5. Galle PR, Forner A, Llovet JM, et al. EASL clinical practice guidelines: management of hepatocellular carcinoma. J Hepatol. 2018;69 (1):182-236. doi:10.1016/j.jhep.2018.03.019

6. Marrero JA, Kulik LM, Sirlin CB, et al. Diagnosis, staging, and management of hepatocellular carcinoma: 2018 practice guidance by the American association for the study of liver diseases. Hepatology. 2018;68(2):723-750. doi:10.1002/hep.29913

7. Omata M, Cheng AL, Kokudo N, et al. Asia-Pacific clinical practice guidelines on the management of hepatocellular carcinoma: a 2017 update. Hepatol Int. 2017;11(4):317-370. doi:10.1007/s12072-0179799-9

8. Debruyne EN, Delanghe JR. Diagnosing and monitoring hepatocellular carcinoma with alpha-fetoprotein: new aspects and applications. Clin Chim Acta. 2008;395(1-2):19-26. doi:10.1016/j.cca.2008.05. 010

9. Carr BI, Akkiz H, Üsküdar O, et al. HCC with low- and normal-serum alpha-fetoprotein levels. Clin Pract (Lond). 2018;15 (1):453-464. doi:10.4172/clinical-practice.1000393

10. Cox TR, Erler JT. Remodeling and homeostasis of the extracellular matrix: implications for fibrotic diseases and cancer. DMM Dis Model Mech. 2011;4(2):165-178. doi:10.1242/dmm.004077

11. Affo S, Yu L-X, Schwabe RF. The role of cancer-associated fibroblasts and fibrosis in liver cancer. Annu Rev Pathol Mech Dis. 2017;12(1):153-186. doi:10.1146/annurev-pathol-052016-100322

12. Masuzaki R, Tateishi R, Yoshida H, et al. Prospective risk assessment for hepatocellular carcinoma development in patients with chronic hepatitis C by transient elastography. Hepatology. 2009;49 (6): 1954-1961. doi:10.1002/hep.22870

13. Cox TR, Bird D, Baker AM, et al. LOX-mediated collagen crosslinking is responsible for fibrosis-enhanced metastasis. Cancer Res. 2013;73(6):1721-1732. doi:10.1158/0008-5472.CAN-12-2233

14. Grenard P, Bresson-Hadni S, El Alaoui S, Chevallier M, Vuitton DA, Ricard-Blum S. Transglutaminase-mediated cross-linking is involved in the stabilization of extracellular matrix in human liver fibrosis. $J$ Hepatol. 2001;35(3):367-375. doi:10.1016/S0168-8278(01)00 $135-0$
15. Wong CCL, Tse APW, Huang YP, et al. Lysyl oxidase-like 2 is critical to tumor microenvironment and metastatic niche formation in hepatocellular carcinoma. Hepatology. 2014;60(5):1645-1658. doi: $10.1002 /$ hep. 27320

16. Sun Y, Mi W, Cai J, et al. Quantitative proteomic signature of liver cancer cells: tissue transglutaminase 2 could be a novel protein candidate of human hepatocellular carcinoma. $J$ Proteome Res. 2008;7(9):3847-3859. doi:10.1021/pr800153s

17. Yu C, Cao Q, Chen $\mathrm{P}$, et al. Tissue transglutaminase 2 exerts a tumor-promoting role in hepatitis B virus-related hepatocellular carcinoma. Tumor Biol. 2016;37(12):16269-16274. doi:10.1007/ s13277-016-5425-z

18. Gulubova MV. Collagen type III and type IV detection in and around human hepatocellular carcinoma. Gen Diagnostic Pathol. 1997;142 (3-4):155-163.

19. Karsdal MA, Henriksen K, Nielsen MJ, et al. Fibrogenesis assessed by serological type III collagen formation identifies patients with progressive liver fibrosis and responders to a potential antifibrotic therapy. Am J Physiol - Gastrointest Liver Physiol. 2016;311(6): G1009-G1017. doi:10.1152/ajpgi.00283.2016

20. Nielsen MJ, Kazankov K, Leeming DJ, et al. Markers of collagen remodeling detect clinically significant fibrosis in chronic hepatitis $\mathrm{C}$ patients. PLoS One. 2015;10(9):e0137302. doi:10.1371/journal. pone. 0137302

21. Nielsen MJ, Veidal SS, Karsdal MA, et al. Plasma Pro-C3 (N-terminal type III collagen propeptide) predicts fibrosis progression in patients with chronic hepatitis C. Liver Int. 2015;35(2):429-437. doi:10.1111/liv.12700

22. Leeming DJ, Karsdal MA, Byrjalsen I, et al. Novel serological neo-epitope markers of extracellular matrix proteins for the detection of portal hypertension. Aliment Pharmacol Ther. 2013;38 (9):1086-1096. doi:10.1111/apt.12484

23. Praktiknjo M, Lehmann J, Nielsen MJ, et al. Acute decompensation boosts hepatic collagen type III deposition and deteriorates experimental and human cirrhosis. Hepatol Commun. 2018;2(2):211-222. doi:10.1002/hep4.1135

24. Nielsen MJ, Thorburn D, Leeming DJ, et al. Serological markers of extracellular matrix remodeling predict transplant-free survival in primary sclerosing cholangitis. Aliment Pharmacol Ther. 2018;48 (2):179-189. doi:10.1111/apt.14806

25. Karsdal MA, Hjuler ST, Luo Y, et al. Assessment of liver fibrosis progression and regression by a serological collagen turnover profile. Am J Physiol - Gastrointest Liver Physiol. 2019;316(1):G25-G31. doi:10.1152/ajpgi.00158.2018

26. Daniels SJ, Leeming DJ, Eslam M, et al. ADAPT: an algorithm incorporating PRO-C3 accurately identifies patients with NAFLD and advanced fibrosis. Hepatology. 2019;69(3):1075-1086. doi:10. 1002/hep.30163

27. Lipton A, Leitzel K, Ali SM, et al. High turnover of extracellular matrix reflected by specific protein fragments measured in serum is associated with poor outcomes in two metastatic breast cancer cohorts. Int $J$ Cancer. 2018;143(11):3027-3034. doi:10.1002/ ijc. 31627

28. Jensen C, Madsen DH, Hansen M, et al. Non-invasive biomarkers derived from the extracellular matrix associate with response to immune checkpoint blockade (anti-CTLA-4) in metastatic melanoma patients. J Immunother Cancer. 2018;6(1):152. doi:10.1186/s40425018-0474-Z

29. Liu SB, Ikenaga N, Peng ZW, et al. Lysyl oxidase activity contributes to collagen stabilization during liver fibrosis progression and limits spontaneous fibrosis reversal in mice. FASEB J. 2016;30 (4):1599-1609. doi:10.1096/fj.14-268425

30. Nielsen MJ, Nedergaard AF, Sun S, et al. The neo-epitope specific PRO-C3 ELISA measures true formation of type III collagen associated with liver and muscle parameters. Am J Transl Res. 2013;5 (3):303-315. 
31. DeLong ER, DeLong DM, Clarke-Pearson DL. Comparing the areas under two or more correlated receiver operating characteristic curves: a nonparametric approach. Biometrics. 1988;44(3):837. doi:10.2307/ 2531595

32. Tangkijvanich P, Anukulkarnkusol N, Suwangool P, et al. Clinical characteristics and prognosis of hepatocellular carcinoma: analysis based on serum alpha-fetoprotein levels. J Clin Gastroenterol. 2000;31(4):302-308. doi:10.1097/00004836-200012000-00007

33. Forner A, Reig M, Bruix J. Hepatocellular carcinoma. Lancet. 2018;391(10127):1301. doi:10.1016/S0140-6736(18)30010-2

34. Ju MJ, Qiu SJ, Fan J, et al. Peritumoral activated hepatic stellate cells predict poor clinical outcome in hepatocellular carcinoma after curative resection. Am J Clin Pathol. 2009;131(4):498-510. doi:10.1309/ AJCP86PPBNGOHNNL

35. Lau EYT, Lo J, Cheng BYL, et al. Cancer-associated fibroblasts regulate tumor-initiating cell plasticity in hepatocellular carcinoma through c-Met/FRA1/HEY1 signaling. Cell Rep. 2016;15 (6):1175-1189. doi:10.1016/j.celrep.2016.04.019

36. Levental KR, Yu H, Kass L, et al. Matrix crosslinking forces tumor progression by enhancing integrin signaling. Cell. 2009;139 (5):891-906. doi:10.1016/j.cell.2009.10.027

37. Kehlet SN, Willumsen N, Armbrecht G, et al. Age-related collagen turnover of the interstitial matrix and basement membrane: implications of age- and sex-dependent remodeling of the extracellular matrix. PLoS One. 2018;13(3):e0194458. doi:10.1371/journal. pone. 0194458
38. Durand F, Valla D. Assessment of the prognosis of cirrhosis: Child-Pugh versus MELD. J Hepatol. 2005;42(SUPPL. 1):S100 S107. doi:10.1016/j.jhep.2004.11.015

39. Peng SY, Chen WJ, Lai PL, Jeng YM, Sheu JC, Hsu HC. High $\alpha-$ fetoprotein level correlates with high stage, early recurrence and poor prognosis of hepatocellular carcinoma: significance of hepatitis virus infection, age, p53 and $\beta$-catenin mutations. Int J Cancer. 2004;112 (1):44-50. doi:10.1002/ijc.20279

40. Bai DS, Zhang C, Chen P, Jin SJ, Jiang GQ. The prognostic correlation of AFP level at diagnosis with pathological grade, progression, and survival of patients with hepatocellular carcinoma. Sci Rep. 2017;7(1):12870. doi:10.1038/s41598-017-12834-1

41. Nissen NI, Karsdal M, Willumsen N. Collagens and cancer associated fibroblasts in the reactive stroma and its relation to cancer biology. J Exp Clin Cancer Res. 2019;38(1):115. doi:10.1186/ s13046-019-1110-6

42. Benson AB, Wainberg ZA, Hecht JR, et al. A phase II randomized, double-blind, placebo-controlled study of simtuzumab or placebo in combination with gemcitabine for the first-line treatment of pancreatic adenocarcinoma. Oncologist. 2017;22(3):241. doi:10.1634/theoncologist.20170024

43. Daneshpour N, Griffin M, Collighan R, Perrie Y. Targeted delivery of a novel group of site-directed transglutaminase inhibitors to the liver using liposomes: a new approach for the potential treatment of liver fibrosis J Drug Target. 2011;19(8):624-631. doi:10.3109/1061186X.2010. 531731
Journal of Hepatocellular Carcinoma

\section{Publish your work in this journal}

The Journal of Hepatocellular Carcinoma is an international, peerreviewed, open access journal that offers a platform for the dissemination and study of clinical, translational and basic research findings in this rapidly developing field. Development in areas including, but not limited to, epidemiology, vaccination, hepatitis therapy, pathology and molecular tumor classification and prognostication are all considered for publication. The manuscript management system is completely online and includes a very quick and fair peer-review system, which is all easy to use. Visit http://www.dovepress.com/ testimonials.php to read real quotes from published authors. 